\section{Edrucasáa

\section{Editor}

Maria Inês Côrte Vitoria PUCRS, RS, Brasil

\section{Equipe Editorial}

Pricila Kohls dos Santos PUCRS, RS, Brasil

Marcelo Oliveira da Silva PUCRS, RS, Brasil

Carla Spagnolo

PUCRS, RS, Brasil

Rosa Maria Rigo

PUCRS, RS, Brasil

\section{ISSN 2179-8435}

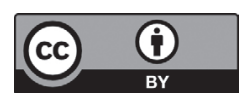

Este artigo está licenciado sob forma de uma licença Creative Commons Atribuição 4.0 Internacional, em qualquer meio, desde que a publicação original seja corretamente citada http://creativecommons.org/licenses/by/4.0/deed.pt_BB

\title{
Afinal, para que servem a história e a filosofia da biologia?
}

\author{
After all, do history and philosophy of biology play any role?
}

\section{Pâmela Ziliotto Sant'Anna Flacha, José Claudio del Pinob}

RESUMO: O presente trabalho pretende discutir a seguinte questão: afinal, para que serve a história e a filosofia da biologia, levando em conta a aprendizagem e o ensino da ciência biológica na escola básica. Para isso, apresentamos uma revisão teórica acerca dos elementos da história da ciência, como o reducionismo, que influenciaram a constituição da biologia enquanto ciência e também elementos históricos da construção da teoria da evolução biológica. Tal discussão justifica-se tendo em vista que a biologia, campo florescente de investigação, de pesquisas e descobertas, não raro, é ensinada e aprendida na escola como uma ciência a-histórica, estática e descontextualizada. Argumentamos que a teoria da evolução, ao estabelecer uma relação entre os diversos campos da biologia, representa a possibilidade de promover o ensino menos fragmentado dessa ciência juntamente com uma visão integrada dos processos que constituem a vida. A história e a filosofia contribuem para que se reconheça a biologia como uma ciência autônoma, com métodos e princípios diferentes das outras ciências naturais e para que os alunos consolidem uma compreensão sistêmica dos fenômenos biológicos, possibilitando que o conhecimento construído seja mobilizado de maneira significativa na proposição de soluções, ideias, explicações para os fenômenos do cotidiano.

Palavras-chave: história da ciência e da biologia; filosofia da ciência e da biologia; ensino.

ABSTRACT: This work aims to discuss the question: after all, do history and philosophy play any role, considering learning and teaching of biological science in high school. For this, we present a review of elements of the history of science as reductionism, which influenced the constitution of biology as a science. Further, we also present historical elements of the construction of the biological evolution theory. Such discussion is justified considering that biology, as a field of growing investigation, research and discoveries, is often taught and learned as an ahistorical, static and decontextualized science. We argue that the evolution theory might

\footnotetext{
a Bacharel e Licenciada em Ciências Biológicas e Mestre em Ecologia pela Universidade Federal do Rio Grande do Sul. Doutoranda em Educação em Ciências pela mesma universidade. Professora no Instituto Federal Farroupilha, Câmpus Frederico Westphalen.

b Pós-Doutor em ensino de química pela Universidade de Aveiro, Portugal. Professor associado da Universidade Federal do Rio Grande do Sul. Professor do Programa de Pós-graduação em Educação em Ciências: Química da Vida e Saúde e do Programa de Pós-graduação em Química, ambos da Universidade Federal do Rio Grande do Sul.
} 
establish a relationship among the various fields of biology and represents a possibility of promoting more integrated teaching and a systemic view of life processes. History and philosophy contribute to the recognition of biology as an autonomous science, with its own methods and principles. Moreover, students tend to consolidate an integrated understanding of biological phenomena through history and philosophy. In this sense, knowledge is built in significant way to explain everyday phenomena.

Keywords: History of science and biology, philosophy of science and biology, teaching.

\section{Ideias iniciais...}

$\mathrm{N}$ s tempos atuais, a ciência é um tema altamente considerado, a ponto de, aparentemente, haver uma crença amplamente aceita e difundida de que existe algo de especial a seu respeito e no que se refere a seus métodos e resultados (CHALMERS, 1993). Qualquer informação, ideia ou pesquisa que se difunda com a atribuição do termo "cientifico" parece ser dotada de algum tipo de mérito ou confiabilidade especial (CHALMERS, 1993).

Se partirmos do princípio que a essência da ciência é o processo continuado de solução de problemas na busca de um contínuo entendimento do mundo em que vivemos, uma história da ciência é antes de tudo uma história dos problemas da ciência e de suas tentativas de solucionar tais problemas ou tentar compreendê-los mais profundamente (MAYR, 1998). Ademais, "a história da ciência é uma história do desenvolvimento dos princípios que formam a estrutura conceitual da ciência" (MAYR, 1998, p. 15).

A ciência do século XX nos tem mostrado, repetidas vezes, que todos os fenômenos naturais estão, em última análise, interconectados e que suas propriedades essenciais, de fato, derivam de suas relações com outras coisas (CAPRA e LUISI, 2014). Assim, a história da ciência, como muitas vezes foi afirmado, é particularmente adequada como uma primeira introdução à ciência. Ela ajuda a "cobrir a distância entre "crenças gerais" e as atuais descobertas científicas, uma vez que mostra de que maneira e por quais razões a ciência avançou além das crenças do folclore" (MAYR, 1998, p. 35).

\section{A ciência da biologia}

Tomando como exemplo de ciência a biologia, esta constitui um campo próspero de investigação, de pesquisas e descobertas. Os periódicos, revistas científicas e jornais publicam constantemente informações que nos permitem 
testemunhar revoluções sem precedentes na genética, na biologia celular, na neurociência, bem como avanços espetaculares na biologia evolutiva, na antropologia física e na ecologia (MAYR, 2005). Desde o surgimento da biologia enquanto ciência legítima, discussões acerca da sua autonomia e unificação têm sido uma das questões centrais da história da biologia (SMOCOVITIS, 1992). Paralelamente, em meados do século XX, também emerge uma subárea da filosofia da ciência interessada em dedicar-se especificamente a uma reflexão sobre a biologia: a filosofia da biologia (ABRANTES, 2011). Uma das primeiras contribuições introdutórias à filosofia da biologia foi a de David Hull, The Philosophy of Biological Science, de 1974, considerada por Abrantes (2011) como um primeiro texto introdutório abrangente em uma área que ainda está se delimitando.

Claramente a biologia é um tipo de ciência muito diferente das demais, diferindo fundamentalmente no seu objeto de estudo, na sua história, nos seus métodos e na sua filosofia. Quando tentamos explicar o que é, enfim, a biologia, vemos que ela, na verdade, consiste em dois campos bem diferentes: a biologia mecanicista (funcional) e a biologia histórica (MAYR, 2005). De acordo com o autor, a biologia funcional ocupa-se da fisiologia de todos os organismos vivos, especialmente com os processos em níveis celular e moleculares. Já a biologia histórica debruçase sobre os aspectos da evolução dos organismos: como a extinção dos dinossauros, por exemplo, a origem dos seres humanos e das demais espécies, a origem das novidades evolutivas e a explicação da diversidade orgânica (MAYR, 2005)

A ideia de que o passado pode nos ser útil para compreender o presente e para pensar e conjecturar o futuro é muito atraente quando pensamos na ciência, incluindo a biologia. Com isso, várias iniciativas têm sido realizadas no sentido de colocar a história da ciência a serviço do ensino (BIZZO, 1992). A proposta de ensino e aprendizagem conectados aos processos históricos de constituição e construção da ciência pode auxiliar os estudantes a compreender exatamente como esta apreende e não apreende o mundo real, vivido e subjetivo (MATTHEWS, 1995). Nesse contexto, evocar a história e filosofia da ciência para iluminar o ensino tornou-se uma estratégia bastante comum, como verifica-se nos trabalhos de GIL PÉREZ (1992), MATTHEWS (1995), MARTINS (1998), CARNEIRO e GASTAL (2005), LOGUERCIO e DEL PINO (2006), PRESTES e CALDEIRA (2009).

No que se refere ao ensino de biologia, a inclusão da história e filosofia dessa ciência pode oferecer alternativas ao tradicional ensino pautado na transmissão e reprodução de informações e conceitos, tendo como recurso principal o livro didático e a sua transcrição no quadro, negligenciando os avanços científicos produzidos nas últimas décadas (BRASIL, 1998). Assim, neste artigo, apresentamos uma reflexão acerca de prováveis respostas para a seguinte questão: afinal, para que servem a história e a filosofia da biologia? Para isso, inicialmente consideramos necessário revisitarmos também elementos da história e filosofia da ciência, em especial da física, cuja epistemologia prevaleceu por muitos séculos influenciando o pensamento dos filósofos da ciência sobre a natureza. Considerando as principais 
discussões acadêmicas que têm sido desenvolvidas sobre a história e a filosofia da biologia, propomos uma discussão acerca da relevância de se pensar a construção do conhecimento biológico no contexto da escola básica considerando as suas bases históricas e filosóficas.

\section{0 reducionismo na biologia}

Ao olharmos retrospectivamente para a história da ciência, é possível perceber que ela incorporou muitos aspectos fisicalistas. Isso porque a física durante muito tempo serviu de modelo para o que se pensasse sobre ciência devido à grande influência de pensadores como Descartes e Newton.

A filosofia cartesiana, por exemplo, baseava sua visão de natureza na divisão fundamental entre dois domínios independentes e separados: o da mente e o da matéria e concebia o universo material como uma máquina, assim como os organismos vivos, que poderiam, em princípio, ser compreendidos completamente quando analisados em função de suas partes menores (CAPRA e LUISI, 2014). Newton por sua vez desenvolveu uma abrangente formulação matemática da visão mecanicista da natureza, realizando, assim, uma síntese grandiosa das obras de Copérnico e de Kepler, Bacon, Galileu e Descartes (CAPRA e LUISI, 2014).

O movimento fisicalista teve, indubitavelmente, o enorme mérito de refutar grande parte do pensamento mágico que caracterizara os séculos anteriores, fornecendo uma explicação natural dos fenômenos físicos e eliminando, dessa forma, grande parte da confiança no sobrenatural que antes era aceita por quase todo mundo (MAYR, 2008). Quanto à biologia, a demonstração histórica da substituição gradual dessas crenças míticas e pré-científicas, ou primitivamente científicas, por teorias científicas e conceitos mais bem fundamentados ajuda grandemente a explicar a estrutura atual das teorias biológicas (MAYR, 1998).

Para Martinez (2011), o reducionismo pode ser entendido como uma tese metafísica, no sentido de aplicação da tese fisicalista que assevera que todos os fatos são determinados por leis físicas, ou seja, todos os fatos dos quais a ciência se ocupa são de um mesmo tipo ou podem ser desmembrados em fatos do mesmo tipo. Assim, por exemplo as explicações funcionais (como o funcionamento de um determinado órgão ou de dispositivo), tão utilizadas nas ciências sociais e na biologia, deveriam ser reformuladas como derivações a partir de leis gerais (MARTINEZ, 2011).

Desde Descartes, contudo, a ideia do reducionismo confunde-se com a ideia mecanicista de que os diferentes sistemas do mundo são mecanismos-máquinas que diferem apenas em sua complexidade. A partir dessa perspectiva, os fenômenos do mundo são resultado de processos de interação entre esses mecanismos (MARTINEZ, 2011). Disso decorre a ideia de que o todo pode ser conhecido conhecendo-se as características e o funcionamento de suas 
partes. Assim, poderíamos entender todo fenômeno como uma "interação complexa de mecanismos-máquinas, cada um dos quais estaria composto por partes cujo funcionamento explicaria o comportamento do todo" (MARTINEZ, 2011, p. 38).

Parece-nos evidente que a metodologia científica por excelência é aquela proposta pelos reducionistas, tanto que no ensino das ciências, por exemplo, muitos autores identificaram uma associação direta entre o reducionismo e a empreitada científica (EL-HANI, 2000). Na biologia, a visão reducionista demandava que todos os fenômenos vivos fossem analisados até os elementos componentes de nível mais inferior, para mostrar que não restava resíduo algum após tudo ter sido explicado em termos de física e química (MAYR, 2005). De acordo com o autor, isso culminou com a famosa declaração de Berlim pelos fisiologistas Brücke, DuBois-Reymond e Helmholtz: "promover a verdade segundo a qual não há outras forças ativas no mundo orgânico além das forças físicas e químicas comuns" (MAYR, 2005, p. 84).

Inegavelmente, a visão reducionista imprimiu fortes influências sobre a biologia e seu progresso. No século XVII, William Harvey (1578-1657) revolucionou a ciência médica de sua época ao postular explicações para a circulação do sangue nas quais comparava o sistema circulatório a um sistema de dutos, sendo o coração semelhante a uma bomba que faria o sangue circular. Visto dessa perspectiva, o funcionamento de um organismo vivo consistia em um mecanismo complexo feito de partes que, em última instância, obedecem a leis mecânicas e sobre essa base iniciava-se a fisiologia experimental (MARTINEZ, 2011).

Durante a segunda metade do século XIX, o aperfeiçoamento do microscópio levou a muitos notáveis avanços na biologia. Foi nesse período que os biólogos formularam a teoria celular, os princípios da embriologia moderna, promoveram a ascensão da microbiologia e descobriram as leis da hereditariedade. Essas novas descobertas arraigaram firmemente a biologia na física e na química, e os cientistas renovaram seus esforços na busca de explicações físicoquímicas para a vida (CAPRA e LUISI, 2014).

A década de 50 foi marcada pelo triunfo espetacular da genética e pela elucidação da estrutura física do DNA e do código genético. As contribuições científicas da genética permitiram aos biólogos a descoberta de que as características de todos os organismos vivos estavam codificadas em seu genoma, na mesma substância química e através de um mesmo código genético.

O triunfo da biologia molecular resultou na crença difundida amplamente de que as funções biológicas podem ser explicadas com base em estruturas e mecanismos moleculares (CAPRA e LUISI, 2014). Ao mesmo tempo, os problemas que resistem à abordagem mecanicista da biologia molecular tornam-se ainda mais evidentes. Para os autores, embora os biólogos conheçam a estrutura precisa de alguns genes, eles sabem muito pouco sobre as maneiras pelas quais os genes se comunicam e cooperam para o desenvolvimento de um organismo. 
Obviamente, tal interpretação reducionista, de que a compreensão só poderia ser alcançada no nível mais baixo de organização, foi particularmente perturbadora para muitos biólogos, porque a redução a tais níveis abandonava a biologia e lidava basicamente com fenômenos físicos (MAYR, 2005). Assim, a filosofia tradicional da ciência, concebida a partir da física, revelou-se, em parte, inadequada quando os filósofos voltaram sua atenção para a ciência biológica (GRIFFITHS, 2000).

À luz da história e da filosofia é também possível compreender as concepções de estudantes e professores sobre a biologia e o conhecimento biológico. Benson (1984) realizou observações, discussões individuais e registrou conversas realizadas durante as atividades de sala de aula a fim de interpretá-las. Três professores e oito alunos participaram do estudo, de natureza qualitativa. Ao analisar as concepções dos participantes, Benson percebeu que todos os professores apresentavam uma visão positivista em relação à biologia, o que é considerado pelo autor como algo frequente entre os professores e que influencia diretamente nas concepções dos alunos, que também adotam pontos de vista reducionistas frente à biologia e à ciência.

As concepções reducionistas que chegam até a escola podem, na verdade, ser apenas uma extensão da visão reducionista que prevalece ainda em algumas áreas da biologia, como discutido anteriormente. Galleni (2004) é taxativo ao afirmar que frente ao desenvolvimento da biotecnologia e da capacidade das técnicas de alterar a vida, ainda há uma filosofia muito antiga da biologia. Além disso, o autor critica o fato de as biotecnologias curiosamente ainda estarem amplamente baseadas na filosofia de Francis Bacon ${ }^{1}$, apontando para a necessidade de um novo paradigma na biologia com base nas complexas e recentes descobertas científicas dessa área.

No entanto, certo grau de reducionismo na compreensão da biologia pode ser justificado quando se trata da biologia moderna, visto que a nível molecular muitos processos podem ser compreendidos em termos físico-químicos. Chiaraviglio (1969) argumenta que a biologia molecular pode servir como uma ponte entre os níveis de explicação reducionistas e organicistas. Como exemplo, recorremos ao ensino de genética. Jiménez-Aleixandre (2014) sugere levar em conta as características específicas de domínio da epistemologia da genética, em particular as questões sobre determinismo e indeterminação na tentativa de engajar os estudantes e questionar visões reducionistas. Para o autor, isso é possível através de estratégias que priorizem o engajamento dos alunos em práticas epistêmicas, como argumentação, o uso de evidências e de modelos de genética para construir explicações ou o enquadramento das questões de genética em seu contexto social.

\footnotetext{
${ }^{1}$ Francis Bacon (1561-1626) foi um importante filósofo que propôs que o método científico deveria ser ancorado na observação e na experimentação. A coleta de dados extensiva através dessas metodologias proporcionaria um agregado de informações singulares que serviriam de fundamento para formulação de afirmações universais, levando-nos do particular para o todo.
} 
Martinez (2011) assevera que a melhor maneira de tentar superar o reducionismo é justamente dar-se conta que não há razão para rejeitá-lo; na verdade, os diferentes sentidos do reducionismo podem ser vistos como estratégias que nos permitem identificar componentes estáveis de sistemas complexos, os quais posteriormente, precisamos levar em consideração se quisermos entender fenômenos complexos. Nesse sentido, elencar aspectos históricos da construção e consolidação das diferentes teorias científicas através dos séculos pode ser determinante na compreensão de tais fenômenos e do caráter dinâmico da ciência.

\section{NA história da biologia (e da ciência) surge Darwin!}

Há cerca de dois séculos atrás, a maioria das pessoas, inclusive historiadores naturais, acreditava que toda a variedade de seres vivos que habita Terra correspondia exatamente àqueles organismos criados por Deus (MEYER e EL-HANI, 2000). O paleontólogo francês Georges Cuvier (1769-1832) foi um dos grandes defensores da ideia de que todas as espécies que haviam no planeta correspondiam exatamente àquelas criadas por uma força divina e de que elas permaneceriam imutáveis durante toda a sua existência sem que seus descendentes jamais sofressem mudanças significativas. Essa teoria era conhecida como "fixismo".

A partir do século XVIII, a visão fixista passou a ser questionada por um crescente número de naturalistas, cujas observações em campos como a paleontologia, a anatomia e a biologia do desenvolvimento desafiavam a teoria fixista e sugeriam explicações alternativas (MEYER e EL-HANI, 2000). A ideia de que as espécies passavam por um processo de evolução e assim poderiam sofrer transformações significativas, o que explicaria a variedade de espécies observadas, começou a difundir-se, mas sob forte contestação. O estudo dos fósseis na paleontologia, da distribuição geográficas das espécies e a ideia de órgãos vestigiais eram observações importantes que serviam para corroborar a ideia de evolução (MEYER e EL-HANI, 2000). Que as espécies evoluíam, já se suspeitava... Mas como se daria esta evolução e qual o mecanismo que explicaria a origem das espécies ainda eram questões centrais a serem desvendadas.

Jean Baptiste Lamarck (1744-1829), naturalista francês, foi um dos primeiros a propor um mecanismo consistente para explicar o processo evolutivo. Ele afirmava que

[...] a matéria inanimada produz continuamente, por geração espontânea, formas de vida muito simples que progridem em direção a uma maior complexidade e perfeição, graças a uma tendência natural da vida de tornar-se mais complexa (MEYER e EL-HANI, 2000, p. 158). 
Para Lamarck, haveria o que chamamos hoje de influências abióticas que se oporiam à tendência natural de aumentar a complexidade da vida. Apesar de ser conhecido e apresentado nos livros didáticos como defensor da ideia de uso e desuso dos órgãos e estruturas como condição para o seu desenvolvimento ou atrofia e pela herança dos caracteres adquiridos, tais ideias não eram o cerne de sua teoria, mas tinham um caráter secundário servindo como explicação para interromper a regularidade no aumento de complexidade nos seres vivos (MEYER e EL-HANI, 2000).

A história desse episódio que ilustra uma primeira tentativa consistente de explicar o mecanismo evolutivo constitui um exemplo do quanto a história da biologia e da ciência não podem ser negligenciadas. Para Mayr,

O historiador de biologia deve esforçar-se por apresentar um relato melhor balanceado. Muitas teorias, hoje rejeitadas, como a hereditariedade dos caracteres adquiridos esposada por Lamarck, pareciam formalmente tão consistentes com os fatos que os autores não sofriam críticas por haverem adotado essas teorias dominantes, embora há tempo se tenham revelado erradas (1998, p. 27).

Apesar dos esforços de Lamarck e de vários outros filósofos e naturalistas em explicar como as espécies evoluíam e através de quais mecanismos as espécies teriam se originado, o conceito de organismos criados e essencialmente estáveis, imutáveis continuava soberano até que Charles Darwin (1809-1882) o confrontasse. Darwin tinha plena consciência de que a mudança de uma espécie para outra era o problema mais fundamental da evolução e uma vez isso elucidado, o pensamento evolucionista poderia, finalmente, consolidar-se (MAYR, 1998).

Um dos aspectos mais fascinantes da sua obra é o modo como Darwin reuniu uma série de ideias e de observações em campo em uma teoria revolucionária, a teoria da seleção natural (MEYER e EL-HANI, 2000). Tal teoria postulava que os organismos são dotados de grande fertilidade, a ponto de suas populações tenderem a aumentar exponencialmente caso haja recursos disponíveis para sua sobrevivência. Como a população tende a crescer, são produzidos mais indivíduos do que a quantidade que pode ser suportada pelo ambiente, devendo ocorrer uma dura luta pela existência através da competição pelos recursos do meio.

Outro postulado importante, é a geração de variabilidade dentro das populações. Se observarmos, por exemplo, uma ninhada de gatos, logo perceberemos que os filhotes diferem entre si em diferentes caracteres. Para Darwin, parte dessa variação poderia ser transmitida aos descendentes. Assim, a variabilidade dentro de uma população afetaria diretamente a chance de sobrevivência dos indivíduos na disputa pelos recursos limitados do ambiente.

Diante da limitação de recursos, sobrevivem aqueles seres com características que aumentam sua eficácia na exploração do ambiente no qual vivem. Se a característica responsável pelo aumento na chance de sobrevivência for herdável, ela será passada às novas gerações (MEYER e EL-HANI, 2000, p. 164).

Educação Por Escrito, Porto Alegre, v. 7, n. 2, p. 236-252, jul.-dez. 2016 
A produção de variação entre os indivíduos de uma população e a verdadeira seleção natural são partes inseparáveis de um processo único.

Na primeira fase, a variação é produzida por mutação, recombinação e efeitos ambientais, e na segunda fase os fenótipos variados são separados por seleção. Obviamente, durante a seleção sexual ocorre seleção real. A seleção natural é a força motriz da evolução orgânica e representa um processo largamente desconhecido na natureza inanimada (MAYR, 2005, p. 47).

As descobertas acerca da teoria da evolução de Darwin foram um marco importantíssimo na história da ciência, pois permitiram que a visão até então fisicalista da biologia fosse questionada e que muitos conceitos básicos das ciências físicas aplicados à biologia fossem contestados. Assim, o darwinismo tornou-se o alicerce de um novo paradigma para explicar a "vida" (MAYR, 2008), a ponto de Dobzhansky (1973) asseverar que à luz da evolução, a biologia é, talvez, a ciência intelectualmente mais gratificante e inspiradora. Logo, a evolução assumiu um papel central e unificador na biologia, organizando as diversas disciplinas que a compõe em torno de um eixo comum (MEYER e EL-HANI, 2000). Somente com a evolução, que desafiou a redução à física e à química por causa de seus componentes metafísicos, ao mesmo tempo que introduziu um agente de causa mecânica de mudança evolutiva, a biologia pôde reivindicar sua autonomia enquanto ciência (SMOCOVITIS, 1992).

Vários autores concordam que conceber a evolução biológica enquanto eixo unificador da biologia possibilita a compreensão de temas atuais dessa disciplina na escola de maneira mais integradora e sistematizada (MEGLHIORATTI, 2004; MEYER e EL-HANI, 2005; CORRÊA et al., 2010), contribuindo para combater uma visão distorcida e simplista das teorias biológicas (BIZZO, 1991). Não fosse a evolução, a biologia enquanto ciência se tornaria um amontoado de diversos fatos, alguns interessantes ou curiosos, mas que não fariam nenhum sentido como um todo (DOBZHANSKY, 1973). À luz da teoria evolutiva, foi possível buscar a integração das diferentes áreas da biologia visando ao seu estabelecimento como disciplina científica bem definida (SMOCOVITIS, 1992).

Através de episódios históricos, como, por exemplo, as diferentes teorias propostas por Lamarck e Darwin (isso para não citar outros tantos naturalistas) que concorreram para explicar a evolução biológica, a ciência revela-se como um processo lento de desenvolvimento de conceitos até as concepções aceitas atualmente. Para Martins,

Isso pode facilitar o aprendizado do próprio conteúdo científico que estiver sendo trabalhado. O educando perceberá que suas dúvidas são perfeitamente cabíveis em relação a conceitos que levaram tanto tempo para serem estabelecidos e que foram tão difíceis de atingir (1998, p. 18). 
Acreditamos que a compreensão da evolução pelos estudantes como elo integrador da biologia contribua para enriquecer suas concepções sobre a constituição da biologia enquanto ciência e promover a construção do conhecimento que incorpore as peculiaridades e especificidades que emergem a partir de um olhar retrospectivo e complexo para história dessa ciência. Nesse caso, uma análise histórica mostrará aos estudantes que a ciência muda no decorrer do tempo e que ela é feita por seres humanos falíveis que podem aperfeiçoar o conhecimento, o que não significa que suas propostas possam ser consideradas definitivas (MARTINS, 1998). Tal síntese evolutiva, ao mesmo tempo, pode colocar em discussão as heranças fisicalistas como o determinismo e o reducionismo.

\section{A história e a filosofia da biologia na escola básica}

Apresentar e discutir a visão determinista e a sua tentativa de ruptura pela biologia na escola permite que os alunos compreendam a ciência como uma atividade dinâmica, (re)construtiva, na qual novas hipóteses, novas perguntas e novas descobertas são sempre provisórias, podendo ser constantemente questionadas e substituídas. Aprendam, logo, que "o caminho da ciência nunca é linear" (MAYR, 1998, p. 27).

A superação do determinismo e a refutação da possibilidade de predição absoluta pela biologia pode ser desenvolvida, por exemplo, através da leitura e discussão de textos históricos, oriundos de fontes primárias e secundárias confiáveis com vistas a suscitar nos alunos reflexões sobre as suas concepções iniciais acerca da teoria evolutiva (CORRÊA et al., 2010). Para Mayr,

[...] o estudo da história de um campo é a melhor forma de adquirir um conhecimento dos seus conceitos. Somente percorrendo o árduo caminho na elaboração desses conceitos - capacitando-se dos antigos postulados falsos, que tiveram de ser refutados um a um, em outras palavras, conhecendo todos os erros do passado - pode-se ter a esperança de alcançar realmente um conhecimento completo e sadio. Em ciência não se aprende apenas com os erros próprios, mas também com a história dos erros dos outros (1998, p. 36).

A ideia reducionista sustentava que o problema da explicação de um sistema estava resolvido, em princípio, assim que ele fosse reduzido aos seus menores componentes. Recorremos ao princípio hologramático proposto por Edgar Morin para discutir a aplicabilidade do reducionismo à ciência da biologia. Num holograma físico, o menor ponto da imagem do holograma contém a quase totalidade da informação do objeto representado (MORIN, 2011). Nesse caso, cada parte estaria no todo, assim como o todo estaria na parte. No mundo biológico existem tantas interações entre as partes - por exemplo, entre os genes do genótipo, entre as células, entre os organismos - que o 
conhecimento completo das propriedades das menores partes necessariamente oferece apenas uma explicação parcial (MAYR, 2005).

A ideia, pois, do holograma vai além do reducionismo, que só vê as partes, e do holismo, que só vê o todo, concebendo a biologia como uma ciência complexa: "é complexo o que não pode se resumir numa palavra-chave, o que não pode ser reduzido a uma lei nem a uma ideia simples" (MORIN, 2011, p. 5). Nada é mais característico dos processos biológicos do que a interação em todos os níveis de organização; todos os sistemas vivos são redes complexas - isto é, são, em um alto grau, não lineares; e há incontáveis interconexões entre as dimensões biológicas, cognitivas, sociais e ecológicas da vida (CAPRA e LUISI, 2014). É justamente essa interação entre as partes que fornece as características mais pronunciadas à natureza, como um todo, ou ao ecossistema, ao grupo social, aos órgãos de um simples organismo (MAYR, 2005).

Promover um ensino e aprendizagem que contemplem o caráter essencialmente interacionista dos seres vivos e seus componentes permite uma compreensão integrada dos processos que constituem a vida e a sua manutenção, possibilitando que o conhecimento construído seja mobilizado de maneira significativa na proposição de soluções, ideias, explicações para os fenômenos do cotidiano. Quando se ensina (e se aprende) biologia, a expectativa é (ou ao menos deveria ser) a de que se construa uma visão integrada e ordenada dessa ciência, não se limitando apenas à compreensão de termos técnicos e conceitos (EMMECHE e EL-HANI, 2000).

Da mesma forma, o estudo da história da ciência deve evitar que se adote uma visão ingênua (ou arrogante) da ciência, o que levaria o estudante a considerar os conceitos biológicos e científicos como "verdades" ou como algo "que foi provado" e proposto por gênios que nunca cometerem erros (MARTINS, 1998). Por outro lado, defende a autora, a história da ciência deve impedir que o aluno adote uma visão anti-cientificista "de que todo conhecimento nada mais é do que mera opinião, que todas as ideias são equivalentes e que não há motivo para aceitar as concepções científicas" (MARTINS, 1998, p. 18). Nesse caso, a história da ciência mostrará que os biólogos e demais cientistas cometem erros sim, mas não formulam suas teorias e hipóteses sem que haja evidências que as corroborem.

Necessitamos, então, enfrentar o desafio de que já não basta "transmitir" o conhecimento científico produzido, primeiro porque implicaria o entendimento bisonho de conhecimento (como um pacote estabilizado a ser repassado), segundo porque, mesmo implicando conteúdo, a questão maior é como reconstruí-lo infindamente (aprender a vida toda) (DEMO, 2011). Ademais, as oportunidades se geram produzindo conhecimento, assim como fizeram os cientistas no decorrer da história humana, jamais apenas reproduzindo-o. De acordo com o autor, para tanto, é imprescindível saber discutir e questionar o conhecimento científico, seus métodos e suas controvérsias, com atitude crítica e autocrítica. Deste modo, o alfabetizado cientificamente não precisa saber tudo sobre a ciência (nem mesmo 
para os cientistas isso seria possível!), mas necessita ter conhecimentos suficientes de diversas áreas e saber sobre como esses conhecimentos se transformam em contribuições científicas para a sociedade. Assim, a construção ou a produção do conhecimento implica o exercício da curiosidade, sua capacidade crítica de "tomar distância" do objeto, de observá-lo, de delimitá-lo, de "cercar" o objeto ou fazer sua aproximação metódica, sua capacidade de comparar, perguntar (FREIRE, 1996).

É necessário pensarmos o problema do ensino considerando, por um lado, os efeitos cada vez mais graves da compartimentação dos saberes e da incapacidade de articulá-los, uns aos outros; por outro lado, considerando igualmente que a aptidão para contextualizar e integrar é uma qualidade fundamental da mente humana, que precisa ser desafiada, e não atrofiada (MORIN, 2002). De acordo com Daggett (2012), um dos desafios contemporâneos na formação de futuros biólogos é aumentar o papel, as interações e as abordagens da biologia na sua interface com outras disciplinas. Em seu artigo, a autora discute as motivações e inspirações geradas a partir da articulação e colaboração entre a biologia e a filosofia e descreve como essas interações ocorreram e possibilitaram o desenvolvimento e implementação de novas questões biológicas que podem ser abordadas por graduandos a fim de estimular habilidades e competências para resolver problemas prementes globais, tais como a ampla produção de comida, combustíveis, e tornar os cuidados de saúde disponíveis, ao mesmo tempo, evitando a degradação dos recursos renováveis da Terra. Assim, ao aprender e ensinar biologia e ciência não podemos simplesmente isolar uma palavra, uma informação; é necessário ligá-la a um contexto e mobilizar nosso saber, a nossa cultura, para chegar a um conhecimento oportuno e apropriado da mesma (MORIN, 2003).

Chamany e colaboradores (2008) também propõem que se articule o contexto social e a biologia através da história e da filosofia dessa ciência. Segundo as autoras, essa articulação pode estimular os estudantes a conectar o que aprendem com o que vivenciam, a desenvolverem responsabilidade social e promover a alfabetização biológica. Partindo de temas da biologia familiares, como a anemia falciforme, a regulação gênica e energética, por exemplo, as autoras apresentam propostas para integrar as pessoas, o contexto histórico e social e a filosofia para expandir o currículo da biologia na escola. Tal proposta demonstra que a história pode assumir uma tarefa essencial, ajudando a lançar as bases para uma biologia capaz de reunir e promover uma completude, uma visão sistêmica e integradora, para descrever e explicar os fenômenos em todas as esferas dos sistemas naturais (GRAZIANO, 2013).

Acreditamos que a história da biologia pode sim contribuir, e muito, para a compreensão dessa ciência, estendendo suas aplicações para seu ensino e aprendizagem na escola e para o seu reconhecimento como uma ciência autônoma, com métodos e princípios diferentes das outras ciências naturais. Por outro lado, nem sempre o uso da história da ciência se dá de maneira adequada. Quando se aborda aspectos científicos históricos deve-se 
[...] evitar mostrar apenas o "que deu certo", omitindo as dificuldades encontradas e as propostas alternativas. Esse tipo de procedimento contribui para que o educando tenha uma visão tendenciosa a respeito do conteúdo científico que está sendo trabalhado. Deve-se evitar também não considerar ou mesmo desvalorizar a experiência do próprio aluno. Em vez disso, deve-se trabalhar com ela, procurando mostrar que muitas vezes suas ideias são semelhantes às de algumas das etapas pelas quais passou a construção daquele conceito (MARTINS, 1998, p.18).

\section{Considerações finais}

Retomando o questionamento central que motivou a discussão proposta neste trabalho, "afinal, para que servem a filosofia e a história da biologia?”, podemos destacar inúmeras contribuições dessas duas áreas à ciência, à biologia e ao seu ensino e aprendizagem na escola básica, como:

- Promover a compreensão da ciência como uma construção e não como algo que está pronto, delimitado e livre de questionamentos. Para Demo (2011), o primeiro gesto do conhecimento é sempre desconstrutivo (questionador), para, depois se tornar reconstrutivo (propositivo) e permanecer sempre aberto, discutível. Sobretudo, destacamos que "a ciência produz conhecimentos e desconhecimentos" (SANTOS, 2010, p. 55).

- Promover uma reflexão sobre os aspectos que influenciaram o modo de pensar e fazer da biologia e que a constituíram como ciência. Para Mayr (1998, p.37), é totalmente impossível tentar entender o desenvolvimento de qualquer conceito particular, ou problema, na história da biologia, sem previamente ter a resposta para as seguintes questões: “o que é ciência?", "qual é o lugar da biologia entre as ciências?", "qual é a estrutura conceitual da biologia?".

- Apresentar a biologia como uma ciência complexa, que rejeita a necessidade de uma opção radical pelo reducionismo ou por uma visão mais holística de ciência. Para Morin (2011), a complexidade é um tecido de acontecimentos, ações, interações, retroações determinações, acasos, que constituem o nosso mundo e a nossa realidade. Assim, a complexidade refuta o pensamento simplificador, que desintegra, mutila, reduz. É inegável a importância da herança fisicalista do reducionismo em várias áreas da biologia funcional, como anatomia, biotecnologia, genética, biologia molecular. No entanto, para que a ciência nessas áreas possa avançar, é preciso ir além do reducionismo, considerando a complexidade dos sistemas vivos, ricos em propriedades emergentes, nas quais novos grupos de propriedades sempre surgem em cada nível de integração (MAYR, 2005). 
- Compreender a evolução como o eixo integrador da biologia. A teoria evolucionista tornou-se a "ciência central" da biologia ao unir e relacionar práticas heterogêneas da biologia em uma ciência unificada e progressiva (SMOCOVITIS, 1992).

- Reconhecer o caráter histórico e humano da ciência. Ao pesquisar respostas para questões do mundo real, como as consequências ecológicas do aquecimento global, o delineamento de planos para a conservação de espécies, a compreensão das dinâmicas das paisagens e da expressão gênica, os biólogos constantemente tomam decisões baseadas em princípios filosóficos, como criar testes e explicações para um fenômeno observado (ORZAC, 2012). Para o bem ou para o mal, algum tipo de filosofia é sempre parte integrante do fazer da biologia. Essa filosofia perpassa necessariamente pelo caráter histórico da ciência, que, obviamente, não possui todas as respostas para todas as questões que propomos diariamente.

Porém, a história da ciência pode nos fornecer algumas respostas sim! Pode humanizar a ciência e aproximá-la dos interesses pessoais, éticos, culturais e políticos da comunidade; pode tornar sua aprendizagem mais desafiadora e reflexiva, permitindo, deste modo, o desenvolvimento do pensamento crítico; pode contribuir para um entendimento mais integral dos conceitos científicos, isto é, pode contribuir para a superação do mar de falta de significação que se diz ter inundado as salas de aula, onde fórmulas e equações são recitadas sem que muitos cheguem a saber o que significam; pode melhorar a formação do professor auxiliando o desenvolvimento de uma epistemologia da ciência mais rica e mais autêntica, ou seja, de uma maior compreensão da estrutura das ciências bem como do espaço que ocupam no sistema intelectual das coisas (MATTHEWS, 1995).

Por fim, Galleni (2004) recorda-nos que a principal descoberta científica do século XX é que vivemos em um planeta com recursos limitados e regulados por frágeis equilíbrios. Essa descoberta demanda uma visão de progresso científico diferente, mais voltada para a conservação da biosfera do que para sua modificação. A necessidade de um novo paradigma na biologia, baseado nas descobertas recentes vai ao encontro de uma perspectiva mais integradora, sistêmica que perpassa necessariamente por discussões acerca da sua história e constituição enquanto ciência.

\section{Referências}

ABRANTES, Paulo Cesar Coelho. Introdução: o que é filosofia da biologia? In: ABRANTES, Paulo Cesar Coelho (Org). Filosofia da Biologia. Porto Alegre: Artmed, 2011. p. 11-36.

BENSON, Garth. Teachers' and students' understandings of biology. Doctoral thesis. 1984. Theses (Doctor of Philosophy) - Faculty of Graduate Studies and Research, University of Alberta, Alberta, 1984. Disponível em: <http://files.eric.ed.gov/fulltext/ED280683. pdf $>$. Acesso em: 18 de junho de 2015. 
BIZZO, Nélio Marco Vincenzo. Ensino de Evolução e História do darwinismo. 1991. Tese (Doutorado em Educação) - Faculdade de Educação, Universidade de São Paulo, São Paulo, 1991.

BIZZO, Nelio Marco Vincenzo. História da ciência e ensino: onde terminam os parelelos possíveis? Em Aberto, v. 11, n. 2, p. 29-35, 1992.

BRASIL, Secretaria de Educação Fundamental. Parâmetros curriculares nacionais: Ciências Naturais/Secretaria de Educação Fundamental. Brasília: MEC/SEF, 1998.

CAPRA, Fritjof; LUISI, Pier Luigi. A visão sistêmica da vida: uma concepção unificada e suas implicações filosóficas, políticas, sociais e econômicas. São Paulo: Cultrix, 2014.

CARNEIRO, Maria Helena da Silva Carneiro; GASTAL, Maria Luiza Gastal. História e filosofia das ciências no ensino de biologia. Ciência \& Educação, v. 11, n. 1, p. 33-39, 2005.

CHIARAVIGLIO, Lucio. Reductionistic inferences in modern biology. 1969. Disponível em: <http://search.proquest.com/docview /64354153 ?accountid=26641 $>$. Acesso em: 18 de junho de 2015 .

CHALMERS, Alan. O que é ciência afinal? São Paulo: Brasiliense, 1993.

CHAMANY, Katayoun; ALLEN, Deborah; TANNER, Kimberly. Making Biology Learning Relevant to Students: Integrating People, History, and Context into College Biology Teaching. CBE - Life Sciences Education, v. 7, n. 3, p. 267-278, 2008.

CORRÊA, André Luis; ARAÚJO, Elaine Nicolini Nabuco; MEGLHIORATTI, Fernanda Aparecida; CALDEIRA, Ana Maria de Andrade Caldeira. História e Filosofia da Biologia como ferramenta no Ensino de Evolução na formação inicial de professores de Biologia. Filosofia e História da Biologia, v. 5, n. 2, p. 217-237, 2010.

DAGGETT, Melissa. A role for history and philosophy of biology in exploring new questions in biology. Bioscene: Journal of College Biology Teaching, v. 38, n. 2, p. 43-47, 2012.

DEMO, Pedro. 2011. Praticar ciência: metodologia do conhecimento científico. São Paulo: Saraiva, 2011.

DOBZHANSKY, Theodosius. Nothing in Biology makes sense except in the light of evolution. American Biology Teacher, v. 35, n. 3, p. 125-129, 1973.

EL-HANI, Charbel Niño. Níveis da ciência, níveis da realidade: evitando o dilema holismo/reducionismo no ensino de ciências e biologia. 2000. Tese (Doutorado em Educação) - Faculdade de Educação, Universidade Estadual de São Paulo, 2000.

EMMECHE, Claus; EL-HANI, Charbel Niño. Definindo vida. In: EL-HANI, Charbel Niño; VIDEIRA, Antonio Augusto Passos (Org.). O que é vida? Para entender a Biologia do século XXI. Rio de Janeiro: Relume Dumará, 2000. p. 31-56.

FREIRE, Paulo. Pedagogia da autonomia: saberes necessários à prática educativa. São Paulo: Paz e Terra, 1996.

GALLENI, Lodovico. Biodiversity, biotechnologies and the philosophy of biology. Rivista di Biologia, v. 97, n. 2, p. 205-222, 2004.

GIL PÉREZ, Daniel. Contribución de la historia y de la filosofía de las ciencias al desarrollo de un modelo de enseñanza/aprendizaje como investigación. Enseñanza de las Ciencias, v. 11, n. 2, p. 197-212, 1992. 
GRAZIANO, Mario. Philosophy of biology. Is there still a need for philosophy? Theoretical Biology Forum, v. 106, n. 1-2, p. 147-156, 2013.

GRIFFITHS, Paul. David Hull's Natural Philosophy of Science. Biology and Philosophy, v. 15, p. 301-310, 2000.

JIMÉNEZ-ALEIXANDRE, María Pilar. Determinism and underdetermination in genetics: implications for students' engagement in argumentation and epistemic practices. Science \& Education, v. 23, n. 2, p. 465-484, 2014.

LOGUERCIO, Rochele de Quadros; DEL PINO, José Cláudio. Contribuições da História e da Filosofia da Ciência para a construção do conhecimento científico em contextos de formação profissional da química. Acta Scientiae, v. 8, n. 1, p. 67-77, 2006.

MARTINEZ, Sergio, Fernando. Reducionismo em biologia: uma tomografia da relação biologia-sociedade. In: ABRANTES, Paulo Cesar Coelho (Org.). Filosofia da Biologia. Porto Alegre: Artmed, 2011. p. 37-52.

MARTINS, Lilian Al-Chueyr Pereira. A história da ciência e o ensino da biologia. Ciência e Ensino, v. 5, p. 18-21, 1998.

MATTHEWS, Michael. História, Filosofia e Ensino de Ciências: a tendência atual de reaproximação. Caderno Catarinense do Ensino de Física, v. 12, n. 3, p. 164-214, 1995.

MAYR, Ernst. Desenvolvimento do pensamento biológico: diversidade, evolução e herança. Brasília, DF: Editora Universidade de Brasília, 1998.

MAYR, Ernst. Biologia, ciência única: reflexões sobre a autonomia de uma disciplina científica. São Paulo: Companhia das Letras, 2005.

MAYR, Ernst. Isto é biologia: a ciência do mundo vivo. São Paulo: Companhia das Letras, 2008.

MEGLHIORATTI, Fernanda Aparecida. História da construção do conceito de evolução biológica: possibilidades de uma percepção dinâmica da ciência pelos professores de Biologia. 2004. Dissertação (Mestrado em Educação para a Ciência) - Faculdade de Ciências, Universidade Estadual Paulista Júlio de Mesquita Filho, Bauru, 2004.

MARTINS, Lilian Al-Chueyr Pereira. A história da ciência e o ensino de biologia. Ciência \& Ensino, v. 5, p. 18-21, 1998.

MEYER, Diogo; EL-HANI, Charbel Niño. Evolução. In: EL-HANI, Charbel Niño; VIDEIRA, Antonio Augusto Passos. O que é vida? Para entender a Biologia do século XXI. Rio de Janeiro: Relume Dumará, 2000. p. 153-185.

MEYER, Diogo; EL-HANI, Charbel Niño. Evolução: o sentido da biologia. São Paulo: Editora Unesp, 2005.

MORIN, Edgar. A cabeça-bem-feita: repensar a reforma, reformar o pensamento. Rio de Janeiro: Bertrand Brasil, 2002.

MORIN, Edgar. Da necessidade de um pensamento complexo. In: MARTINS, Francisco Menezes; SILVA, Juremir Machado. Para navegar no século 21: tecnologias do imaginário e cibercultura. Porto Alegre: Sulina/Edipucrs, 2003. p. 13-36.

MORIN, Edgar. Introdução ao pensamento complexo. Porto Alegre: Sulina, 2011.

PRESTES, Maria Elice Brzezinski; CALDEIRA, Ana Maria de Andrade. Introdução. A importância da história da ciência na educação científica. Filosofia e História da Biologia, v. 4, p. 1-16, 2009. 
ORZACK, Steven Hecht. The philosophy of modelling or does the philosophy of biology have any use? Philosophical Transactions of the Royal Society Biological Sciences, v. 367, n. 1586, p. 170-180, 2012.

SANTOS, Boaventura Sousa. Um discurso sobre as Ciências. Porto: Edições Afrontamento, 2010.

SMOCOVITIS, Vassiliki Betty. Unifying Biology: The Evolutionary Synthesis and Evolutionary Biology. Journal of the History of Biology, v. 25, n. 1, p. 1-65, 1992.

Recebido em: fevereiro/2016

Aceito em: novembro/2016

Endereço para correspondência:

Pâmela Ziliotto Sant'Anna Flach

Rua Ramiro Barcelos, 2600 - Prédio Anexo

90035-003 Porto Alegre, RS, Brasil

<pamelazsf@gmail.com> 